\title{
Núcleo de Informática na Educação Especial NIEE
}

\author{
Lucila Maria Costi Santarosa ${ }^{1}$, Debora Conforto ${ }^{2}$, Fernanda Chagas Schneider ${ }^{1}$, \\ ${ }^{1}$ Programa de Pós- Graduação em Informática na Educação (PGIE) e ${ }^{1}$ Programa de Pós- \\ Graduação em Educação (PPGEDU) - Universidade Federal do Rio Grande do Sul \\ (UFRGS) - Porto Alegre - RS - Brasil \\ ${ }^{2}$ Secretaria Municipal de Educação (SMED) - Prefeitura de Porto Alegre - Porto Alegre \\ - RS - Brasil \\ lucila.santarosa@terra.com.br, deboraconforto@gmail.com, \\ ferchsceyahoo.com.br
}

O Núcleo de Informática na Educação Especial - NIEE, da Universidade Federal do Rio Grande do Sul-UFRGS, em seus quase 30 anos de história, vem atuando para garantir e ampliar o acesso de pessoas com deficiência aos benefícios das tecnologias digitais de informação e de comunicação. Criado em 1984, a partir da ressignificação de um laboratório de informática oriundo do extinto projeto EDUCOM, o NIEE vem se consolidando como núcleo de pesquisa em excelência no cenário nacional e mundial, assumindo como objetivo o desenvolvimento tecnológico, a pesquisa científica e a formação docente nesta área do conhecimento. Coordenado pela Prof ${ }^{a}$ Dra. Lucila Maria Costi Santarosa, o núcleo conta com uma equipe ${ }^{1}$ de mais de 50 bolsistas, pesquisadores e desenvolvedores que atuam em suas diferentes frentes.

Dos projetos de desenvolvimento tecnológico idealizados pelo NIEE, destacamos o Simulador de Teclado, o Ambiente Virtual de Aprendizagem Eduquito, o Teclado Virtual Silábico-Alfabético - Mousekey e o atual projeto de desenvolvimento da Plataforma EAD acessível que, observando as demandas educacionais por ambientes virtuais de aprendizagem que contemplem a diversidade humana, passa a ser construído considerando as diretrizes de acessibilidade da World Wide Web Consortium (W3C).

No âmbito da investigação, as pesquisas científicas desenvolvidas pelo núcleo consideram como escopo os processos de mediação, observando as dimensões cognitivas, comunicativas e sócio-afetivas dos sujeitos com deficiência. Tais pesquisas contam com a parceria de diversas instituições nacionais e internacionais (RIBIE, CYTED, IBERDISCAP, CIIEE, SICA, SIIE, REDAUTI, dentre outras), e recebem fomento do Ministério da Educação, do CNPq e do MCTI.

Destacamos por fim, a colaboração do NIEE para a formação de recursos humanos. Neste campo, o NIEE já serviu como laboratório para mais de 50 trabalhos, entre dissertações e teses defendidas nos Programas de Pós-Graduação da UFRGS. Além disso, o núcleo oferta o Curso de Formação Continuada em Tecnologias da Informação e Comunicação Acessíveis, ação pela qual já capacitou mais de 7000 professores da rede pública de todo o território nacional.

\footnotetext{
${ }^{1}$ A relação completa da equipe ligada ao NIEE, encontra-se disponível em www.niee.ufrgs.br
} 